Ano 6, Vol. 6 (2), n 2. 2021, julho/dezembro de 2021.

https://doi.org/10.48179/revext.v6i2.306

\title{
Geração beat: experiências místicas, diálogos estéticos e poética das contraculturas
}

\author{
Edvaldo Nunes dos Santos ${ }^{(1)}$
}

(1) Aluno do curso de Letras da Universidade Estadual de Alagoas (UNEAL), campus Arapiraca. Endereço de e-mail: edvaldosanttos8@outlook.com.

Resumo - A geração beat foi um movimento estético-literário que emergiu na América do norte no século passado e culminaria no que se entende por contracultura. Nutridos por um sentimento de inconformidade, advindo dos horrores da segunda guerra e das mazelas trazidas pela ascenção dos modelos capitalistas, alguns jovens adotam um modelo de vida marginal, do qual, surge uma poesia libertária, que comunga com o cosmos a partir de uma visão mística plural e que idealiza um modelo utópico e rebelde de criação, desprendido de regras e fora do cânone. Dentre os principais escritores, podemos citar o célebre poeta Allen Ginsberg, o qual, é responsável por disseminar o pensamento da geração beat entre a juventude da época e que é retomado neste trabalho, onde pretende-se compor um estudo acerca da relação entre produção poética, experiência mística e como essa relação culmina, no grupo citado, na construção de um espaço dialógico. Dadas essas considerações, nos valemos de procedimentos interpretativos e tomamos como arcabouço teórico para tais interpretações autores como: Fryszman (2018), Willer (2009), Ruzzarin (2013). Contudo, buscando mostrar que a literatura de Ginsberg empreende-se sobre um cenário de marginalidade, interlocução e em uma atitude política de representação, diálogo com a transcendencia e também de enfrentamento a qualquer tipo de repressão.

Palavras-chave: Geração beat, Experiência mística, Produção poética.

\section{Beat generation: mystical experiences, aesthetic dialogues and poetics of countercultures}

\begin{abstract}
The beat generation was an aesthetic-literary movement that emerged in North America in the last century and would culminate in what is meant by counterculture. Nourished by a feeling of nonconformity, coming from the horrors of the second war and the ills brought about by the rise of capitalist models, some young people adopt a marginal model of life, from which, emerges a libertarian poetry, which communes with the cosmos from a plural mystical vision and that idealizes a rebellious model of creation , totally detached from rules and out of the canon. Among the main writers, we can mention the famous Allen Ginsberg, who are responsible for disseminating the thought of the beat generation among the youth of the time and who are resumed in this work, where we intend to commend a study about the relationship between poetic production, mystical
\end{abstract}


Ano 6, Vol. 6 (2), no 2. 2021, julho/dezembro de 2021.

https://doi.org/10.48179/revext.v6i2.306

experience and how this relationship culminates, in the group cited, in the construction of a dialogic space. Given these considerations, we use interpretative procedures and take as theoretical framework for such interpretations authors as: Fryszman (2018), Willer (2009), Ruzzarin (2013). However, seeking to show that the literature of Ginsberg is undertaken on a scenario of marginality and a political attitude of representation, dialogue with transcendence and also of coping with any type of repression.

Keywords: Beat generation, Mystical experience, Poetic production.

\section{INTRODUÇÃO}

A bomba de 1945 não só ceifou várias vidas, mas, ela foi responsável por redefinir o pensamento da juventude da época que, ao buscar uma forma de fugir dos horrores da guerra, optou por um desapego aos valores vigentes e, assim, passou a ver a ideia de modernidade com certo temor.

Essa rebeldia foi terreno fértil para um grupo de poetas, os quais, empreenderam um movimento literário, chamado Geração beat, que ganha força em meados da década de 1950. Sobretudo, esses jovens pregavam a paz, de forte relação com correntes religiosas, como o budismo e o catolicismo, enquanto comungavam com a estética de poetas anteriores, como com o romântico William Blake.

A poesia, para muitos dessa geração, era uma arma poderosa. A relação vida e obra fundia-se de maneira que os poemas saiam dos livros, iam ser declamados nas ruas, o que conferia um tom de marginalidade e era fortemente repreendido pela polícia e pela sociedade puritana da época que reprovavam os chamados vagabundos, sobretudo pelo consumo de alucinógenos e pela relação que mantinham com outros grupos fortemente descriminados.

Allen Ginsberg, um dos principais poetas desse movimento, nasceu em 1926, em Nova Jersey. Desde cedo começa a se relacionar com ideais políticos, sobretudo com os comunistas, sendo sua poesia veículo para confrontar as desigualdades e os impasses sociais advindos do capitalismo norte-americano. Contudo, é um dos mais célebres escritores que compuseram a geração beat, lista que conta com nomes como, William Burroughs, Jack Kerouac e Neal Cassady, dentre outros. 
Ano 6, Vol. 6 (2), no 2. 2021, julho/dezembro de 2021. https://doi.org/10.48179/revext.v6i2.306

Por fim, esse pensamento subversivo desembocou no que ficou historicamente conhecido como contracultura e, essa, reuniu todas os preceitos anteriores e os condensou na utopia de um mundo fraterno, que chegaria de maneira mística e que se tornou símbolo de revolução pela poesia e fuga ao sistema vigente.

\section{PROCEDIMENTO METODOLÓGICO}

Intentamos a leitura de poemas de Allen Ginsberg a fim de evidenciar a relação mística que se apresenta em sua literatura, espelho para a construção da identidade estética da geração beat.

Realizamos um levantamento histórico sobre as origens do movimento e como seus ideais configuram-se a partir de uma visão plural e pautados em um modelo de vida subversivo, que também se apresenta na poesia desses sujeitos, sobretudo, como crítica ao modelo social vigente ou o puritanismo.

Fizemos levante de produções teóricas sobre os temas: "geração beat", "Allen Ginsberg", "beats e contracultura", na intenção de produzir uma análise próxima do que real apresenta o material interpretado, assim, levando em conta a época em que fora produzida a obra, o que dizem as interpretações anteriores e, principalmente, como o poeta dialoga com textos outros, os quais, são referenciados a partir do uso de metáforas ou figuras de linguagem.

\section{RESULTADOS E DISCUSSÃO}

Envolto em valores políticos e místicos, Allen Ginsberg misturou em sua literatura religiosidade e obscenidade, enquanto denunciava os horrores que o mundo sucumbira em um período pós-guerra. Seu apego ao transcendente e a denúncia social são muito presentes em seus poemas e, contudo, foram parte muito importante na construção da identidade estética da geração beat.

Por outro lado, também evocava a presença de poetas como William Blake, o qual, afirmava ter contato durante visões, que não se sabe se realmente ocorriam por serem 
Ano 6, Vol. 6 (2), no 2. 2021, julho/dezembro de 2021.

https://doi.org/10.48179/revext.v6i2.306

experiência mística ou eram causadas pelo consumo de drogas, algo muito comum entre os escritores dessa geração.

Em seu poema "Uivo", considerado a obra mais representativa da estética beat, podemos ver claramente a relação entre inconformismo, fuga e transcendência, onde é empreendida uma poesia que se assemelha a uma narrativa, com versos longos e com uma tessitura bem típica, que parece o próprio som de um grito, em conformidade ao próprio título;

\begin{abstract}
Uivo para Carl Solomon I

Eu vi os expoentes da minha geração destruídos pela loucura, morrendo de fome, histéricos, nus ,arrastando-se pelas ruas do bairro negro de madrugada em busca de uma dose violenta de qualquer coisa, "hipsters" com cabeça de anjo ansiando pelo antigo contato celestial com o dínamo estrelado da maquinaria da noite, que pobres, esfarrapados e olheiras fundas, viajaram fumando sentados na sobrenatural escuridão dos miseráveis apartamentos sem água quente, flutuando sobre os tetos das cidades contemplando jazz, que desnudaram seu cérebro ao céu sob o Elevado e viram anjos maometanos cambaleando iluminados nos telhados das casas de cômodos, que passaram por universidades com olhos frios e radiantes alucinando Arkansas e tragédias à luz de William Blake entre os estudiosos da guerra, que foram expulsos das universidades por serem loucos \& publicarem odes obscenas nas janelas do crânio $[\ldots]$
\end{abstract}

(GINSBERG, 1984, pg. 41)

De início, Ginsberg oferece seu poema a Carl Solomon, um grande companheiro da geração beat. $O$ poeta também cita os hipsters, em alusão ao seu próprio grupo, no sentido de referenciar seus modos de vida alternativos e, também os associando a figura do anjo e do sobrenatural.

Alguns trechos parecem referenciar a posição do eu-lírico frente a máquina, símbolo da modernidade, como, "ansiando pelo antigo contato celestial com o dínamo estrelado da maquinaria da noite". Além disso, ele também critica duramente o academicismo em "que foram expulsos das universidades por serem loucos $\&$ publicarem odes obscenas nas janelas do crânio", obviamente, falando de sua relação com os centros acadêmicos e de seu modelo frenético e pouco comum de produção.

As visões de Ginsberg, que o inspiravam a escrever suas próprias experiências de vida, podem ser vistas em sua referência ao poeta no trecho "tragédias à luz de William 
Ano 6, Vol. 6 (2), no 2. 2021, julho/dezembro de 2021.

https://doi.org/10.48179/revext.v6i2.306

Blake" e, contudo, o longo poema se constrói sobre a aparente relação entre a mística, a crítica social, que pode ser lida como um relato das vivências do autor e sua consciência subversiva.

O modelo em que se constrói o poema, o fluxo contínuo, pode se aproximar da escrita de outros nomes da geração beat, como Kerouac, assumindo o que Claudio Willer (2009) chama de "prosódia bop", um tipo de escrita típico da beat que, muitas vezes, aproximava-se da linguagem informal, do jazz. Ao mesmo tempo, as ramificações de palavras geram frases que parecem complementares e acabam por nutrir-se de uma negatividade, que provém da escolha de termos como "morrendo", "histéricos", "nus", "esfarrapados", “cambaleando".

Outro poema emblemático é o "Sutra do girassol". Esse, remete não só a modernidade norte-americana e a mística, mas é espelho da própria relação de Ginsberg com seus amigos beats, já que, Keroauc, que era seu companheiro e ajudou a fundar o movimento, aparece como personagem na obra, discutindo questões existenciais com Allen a partir do olhar sobre uma flor;

\footnotetext{
Olha o Girassol, disse ele, lá estava a sombra cinzenta e morta contra o céu, do tamanho de um homem, encostada ressecada no topo do montão de velha serragem- Ergui-me encantado- meu primeiro girassol, recordações de Blakeminhas visões- Harlem e inferno dos rios do Leste, pontes com o clangor dos Sanduíches Gordurosos de Joe [...]

(GINSBERG, 1984, pg.61)
}

O título evidencia aos Sutras, escrituras em forma de cânticos budistas que repassam conhecimentos milenares; também há uma forte recusa aos ideais americanos na figura do Harlem, um conhecido e movimentado bairro de Nova York, por ele associado ao inferno.

A fragilidade do girassol fica evidente na associação a uma "sombra cinzenta e morta contra o céu" e a flor é associada a William Blake, que possui poemas com a mesma temática e, como dito, é sempre mencionado por Ginsberg em suas prováveis visões.

Além disso, Juli Anna Ruzzarin (2013) acrescenta que há um fluxo de consciência não só neste poema, como em toda poesia de Allen Ginsberg. Segundo ela, em sua poesia 
Ano 6, Vol. 6 (2), no 2. 2021, julho/dezembro de 2021.

https://doi.org/10.48179/revext.v6i2.306

estão presentes marcas textuais como antíteses, comparações e contradições que se sustentam na metáfora da América e vão se intercruzando conturbadamente, em meio à luz e sombras. Ruzzarin também nos lembra que o uso de alucinógenos estava presente durante o processo de escrita dos beats e esse estado anormal que escreviam talvez alavancasse o salto existencial de suas literaturas.

O consumo de drogas, inclusive, fora uma prática comum não só entre os poetas da geração beat mas entre muitos jovens adeptos aos movimentos de contracultura, que viam o uso dessas substâncias como gatilho para provocar experiências e perceber novas formas de realidade ou até mesmo transcendê-las.

Já em outro poema, intitulado "Nota de pé de página para Uivo", Ginsberg evoca a santidade de todas as coisas, do sagrado ao profano. Lembra uma oração ou um mantra, onde a própria constituição do poema nos leva a perceber elementos irônicos e metafóricos; da mesma maneira que os outros, em fluxo contínuo, mais parecendo uma conversa em tom alterado de consciência;

Santo! Santo! Santo! Santo! Santo! Santo! Santo! Santo! Santo! Santo! Santo! Santo! Santo! Santo! Santo!

O mundo é santo! a alma é santa! A pele é santa! O nariz é santo!

[...] Santo o saxofone que geme! Santo o apocalipse bop! Santos a banda de jazz marijuana hipsters paz \& droga \& sonhos!

Santa a solidão dos arranha-céus e calçamentos! Santas as cafeterias cheias de milhões Santo o misterioso rio de lágrimas sob as ruas!

[...] Santas as visões santas as alucinações santos os milagres santo o globo ocular santo o abismo!

Santo perdão! Misericórdia! Caridade! Fé! Santo! Nossos! Corpos! Sofrendo!magnanimidade!

Santa a sobrenatural extra brilhante inteligente bondade da alma! (GINSBERG, 1984, pg. 54-55)

Santifica-se o ritmo, através do "apocalipse bop", a musicalidade através do "jazz marijuana" e a mística das eventuais "visões". No entanto, no que se refere a América, percebemos o caráter de denúncia, sobretudo, em trechos como "santas as cafeterias cheias de milhões" ou em "santo o misterioso rio de lágrimas sob as ruas!", que são trazidos a partir da representação de um modelo consumista- "cheias em milhões"- e de um desencanto atroz- "misterioso rio de lágrimas"- que configuram uma posição política do autor, revelando sua essência contraculturalista através da negação ao modelo cultural 
Ano 6, Vol. 6 (2), no 2. 2021, julho/dezembro de 2021.

https://doi.org/10.48179/revext.v6i2.306

vigente e as configurações sociais, também, demonstrando certa simbiose entre a posição de ativista do poeta e sua produção literária.

Vale lembrar que essa poesia foi escrita depois que "Uivo" já havia sido criado, como nota de rodapé. Assim, parece anteceder toda a violência que o primeiro poema pretendia berrar e, nenhum pouco menor, abre caminho de forma transcendente, construindo-se a partir do caos e da beatitude, como um arauto que anuncia a salvação a partir dos marginais. Nessa perspectiva, Fryszman (2018) confirma que;

A nota de rodapé de "Uivo", acrescentada posteriormente, inicia-se com 15 exclamações de "Santo!", fazendo lembrar a litania dos lunáticos religiosos berrando nas ruas. Ginsberg sugere que, mesmo havendo miséria e exclusão no mundo, ainda será possível uma redenção, e essa salvação virá pelas mãos dos que semearam os valores da geração beat e dos excluídos imbuídos de santidade (FRYSZMAN, 2018, pg. 69).

É importante perceber que o poema traz um simbolismo aparente na relação entre objetos físicos e espirituais e uma aproximação com o apocalipse bíblico, onde os excluídos viriam a ser os expurgadores das mazelas do mundo moderno e promoveriam a comunhão entre toda a humanidade, conforme aponta Fryszman (2018), a partir de uma redenção que seria promovida pela própria geração beat.

Assim, a obra vale-se dos preceitos místicos a partir da anunciação de santidade das coisas e da ideia de salvação apresentada sobre a metáfora da alma santa. Por outro lado, parte das constatações sociais para construir uma crítica em segundo plano e promover uma análise ácida da realidade norte-americana e de suas histerias, o que demarca um caráter transgressor e uma atitude rebelde da poesia.

Em suma, essas figuras transfiguradas e místicas que se apresentam nos poemas de Ginsberg, representam um traço peculiar da geração beat, o apego ao transcendente, amparado sob uma estética marginal. São reflexos do próprio modelo de vida desses sujeitos, na relação com as religiões alternativas, no consumo de alucinógenos, no desapego aos bens de consumo, na comunhão com os esquecidos, no feroz ataque a barbárie da guerra e a sociedade americana.

De um lirismo extremo e ímpar, essas obras transgridem a forma poética canônica, enquanto dialogam com outros poetas místicos de maneira emblemática e na busca de 
Ano 6, Vol. 6 (2), no 2. 2021, julho/dezembro de 2021.

https://doi.org/10.48179/revext.v6i2.306

uma arte que partisse da própria realidade. De caráter epifânico e existencial, sustenta-se no lume de uma geração perdida, mas que, a medida que negava os padrões vigentes da sociedade, se inscrevia para sempre na história e caminhava para se tornar um dos maiores movimentos de rebelião juvenil de seu século, a contracultura.

\section{CONCLUSÃO}

Por fim, lançamos um olhar sobre poesia e mística na geração beat a partir do maior expoente dessa relação, o poeta Allen Ginsberg. Usando sua produção contra uma sociedade americana capitalista e excludente, o escritor recorre ao universo místico para nutrir sua poesia transgressiva, onde sagrado e profano se fundem na construção de uma identidade poética ímpar, típica do movimento literário beat e que adentrou a agitada contracultura posterior.

Outrossim, esta poética é carregada de símbolos religiosos e figuras de linguagem, como metáforas, que servem para referenciar objetos animados e inanimados, na medida em que produz uma crítica aos padrões sociais ou proclama uma fuga por meio da transcendência, das visões, do êxtase.

Inovando na forma, percebemos a sonoridade e um fluxo constante de escrita que, ao se aproximar do próprio pensamento, inaugura um novo modelo de texto, também bem típico do movimento supracitado.

Dialogando com poetas como William Blake, percebemos a presença de estéticas distintas dentro da literatura beat. A qual, também usa o misticismo como forma de evocar um passado literário e seus célebres escritores, seja por meio de experiências espirituais ou por meio do uso de alucinógenos. 
Ano 6, Vol. 6 (2), no 2. 2021, julho/dezembro de 2021. https://doi.org/10.48179/revext.v6i2.306

\section{REFERÊNCIAS}

FRYSZMAN, Noemia Davidovich. Contra o pai e a pátria: o "Uivo" libertário de Allen Ginsberg. Ide (São Paulo) vol.4 no.66 São Paulo jul./dez. 2018.

GINSBERG, Allen. Uivo, Kaddish e outros poemas. Trad. Claudio Willer. Porto Alegre: LP\&M, 1984.

RUZZARIN, Juli Anna. O automatismo psíquico como recurso formal: uma análise da obra de Jack Kerouac, Allen Ginsbeg e Jackson Pollock. Anais XIII Semana de Letras PUCRS, 2013. Disponível em> juliannaruzzarin (pucrs.br)

WILLER, Claudio. Geração beat. Porto Alegre: L\&PM, 2009. 